\title{
Molecular Dynamics and Rheological Properties of Liquid Crystalline Polymer in an Electric Field
}

\author{
Young Chul LeE, Jung Do HuH, ${ }^{*}$ and In Jae ChUNG ${ }^{\dagger}$ \\ Department of Chemical Engineering, Korea Advanced Institute of Science and Technology, \\ P.O. Box 131 Cheongryang, Seoul, Korea \\ *Department of Chemical Engineering, Pohang Science and Technology, \\ P.O. Box 125 Pohang, Kyungbuk, Korea
}

(Received September 18, 1989)

\begin{abstract}
The orientation of the nematic polymer, poly ( $p$-phenylene terephthalamide), in sulfuric acid at $50^{\circ} \mathrm{C}$ was studied in the Poiseuille flow under an electric field. The critical concentration, $c^{*}$, as a reference obtained by polarized light microscopy was in the vicinity of $9 \mathrm{wt} \%(=11.29 \mathrm{vol} \%)$. Since the Poiseuille flow apparatus gave an accurate determination of the Miesowicz viscosity, $\eta_{\mathrm{b}}$, it was poissible to determine the order parameters, $S$, the rotational diffusivity, $\bar{D}_{\mathrm{r}}$, the rest of Miesowicz viscosities, $\eta_{\mathrm{a}}$ and $\eta_{\mathrm{c}}$. The magnitude of three viscosities was in the order of $\eta_{\mathrm{c}}>\eta_{\mathrm{a}}>\eta_{\mathrm{b}}$. Whereas $\eta_{\mathrm{a}}$ and $\eta_{\mathrm{b}}$ decreased with dimensionless concentration, $\eta_{\mathrm{c}}$ exhibited a peculiar form different from the theoretical value. $S$ and $\bar{D}_{\mathrm{r}}$ increased with dimensionless concentration. These results indicate the effect of tube dilation, that is, when rod-like molecules are oriented in one direction, their motion becomes further freer.
\end{abstract}

KEY WORDS Liquid Crystalline Polymer / Electric Field / Miesowicz Viscosity / Order Parameter / Rotational Diffusivity /

The production of ultrahigh strength/high modulus fibers spun from nematic solutions of macromolecules is a topic of interest. Specially the fiber made of $\operatorname{poly}(p$-phenylene terephthalamide) (PPTA) shows very excellent physical properties. PPTA has the chemical structure with a high rigidity and the lyotropic phase in sulfuric acid ${ }^{1,2}$ :

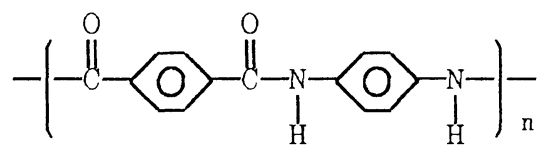

The orientation of a liquid crystalline polymer (LCP), specially PPTA in sulfuric acid, is an important factor in the processing to get a ultrahigh strength fiber. The fascinating aspect of rigid LCPs is that the exceptional physical properties can be obtained without

\footnotetext{
$\dagger$ To whom all correspondence should be addressed.
}

further processing steps. ${ }^{3,4}$

Doi has developed a theory to describe the stress-deformation behavior of LCP solution by generalizing the theory for isotropic and concentrated solutions of rod-like molecules. ${ }^{5-7}$ Marrucci has shown equivalence between the Elicksen-Leslie theory and Doi's molecular theory for small deformation. ${ }^{8}$ Such Doi-Marrucci's theory is based on the lyotropic rigid rod system rather than the thermotropic system. Therefore it is applied to the flow of a lyotropic solution under an electric field.

Lyotropic LCPs such as hydropropylcellulose (HPC) and poly( $\gamma$-benzyl L-glutamate) (PBLG) have been reported to be oriented in an external field and compared with the theoretical prediction. Specially, the orientational order of PBLG molecules in the lyotrop- 
ic state has been extensively studied by means of various methods such as polarized light microscopy, ${ }^{9}$ small angle light scattering, ${ }^{10}$ and X-ray diffraction techniques. ${ }^{11}$ Recently Abe and Yamazaki ${ }^{12}$ observed by using a deuterium NMR that the order parameters, $S$, for PBLG in dimethylformamide increased from 0.795 to 0.945 with concentration. Also Sartirana et $a l .{ }^{13}$ studied for a poly ( $p$-benzamide) (PBA) solution in $N, N$-dimethylacetamide with $3 \%$ $\mathrm{LiCl}$ by using a polarized IR spectroscopy and reported that $S$ increased from 0.76 to 0.83 . They studied $S$ only for the static state under the magnetic field and did not compare the theoretical prediction with rheological properties. Prilutski and Metzner ${ }^{14}$ examined also the behavior of HPC solution in glacial acetic acid for shear and extensional flows and reported $S=0.68$ and $\bar{D}_{\mathrm{r}}=20 \mathrm{~s}^{-1}$ for $40 \mathrm{wt} \%$ concentration. However, the $S$ values of HPC and PBLG solutions are more-or-less deviated from the theoretical values rather than those of the rigid aromatic polyamides because of the flexibility.

While data of Miesowicz viscosities, $\eta_{\mathrm{a}}, \eta_{\mathrm{b}}$, and $\eta_{\mathrm{c}}$, for low molecular weight liquid crystals are available for the flow in presence of magnetic ${ }^{15,16}$ and electric field, ${ }^{17,18}$ none for LCP have been reported yet. Miesowicz viscosity, $\eta_{\mathrm{b}}$, for rods oriented in the direction of the shear flow can be measured due to the fixed orientation of rods by applying an external field. In this study, an electric field was applied to obtained $\eta_{\mathrm{b}}$ for the PPTA solution in sulfuric acid. Once $\eta_{\mathrm{b}}$ is obtained, the orientational order parameter, the rotational diffusivity and the rest of Miesowicz viscosities can be calculated from Doi and Marrucci's theory.

One important point is the choice of critical concentration, $c^{*}$, at which isotropic phases become unstable when the experimental data are compared with the theoretical predictions. Therefore many phase transitional concentrations for different materials have been carefully determined and reported. In this study, a critical concentration was determined using a polarized light microscopy.

\section{THEORY}

The molecular theory developed by Doi describes the dynamics of rod-like polymers in concentrated solutions. ${ }^{5-7}$ Doi's tube model describes the motion of the rods for a given macroscopic flow by means of a kinetic expression for the orientational distribution function and also the molecular motion under the external flow field. ${ }^{19,20}$

The kinetics of the distribution function is described by the following equation;

$$
\frac{\partial f}{\partial t}=\mathscr{R} \cdot \bar{D}_{\mathrm{r}}\left(\mathscr{R} f+\frac{f}{k_{\mathrm{B}} T} \mathscr{R} V\right)+\mathscr{R} \cdot(\omega f)
$$

where $f$ is the distribution function of these vectors and $\omega$ is the angular velocity and $\mathscr{R}$ is the rotational operator:

$$
\mathscr{R}=\boldsymbol{u} \times \frac{\partial}{\partial \boldsymbol{u}}
$$

The potential, $V$, consists of two parts; the potential of the mean field, $V_{\mathrm{MF}}$, and that of the external electric field, $V_{\mathrm{E}}$,

$$
V(\boldsymbol{u} ;[f])=V_{\mathrm{MF}}(\boldsymbol{u} ;[f])+V_{\mathrm{E}}(\boldsymbol{u})
$$

The potential $V_{\mathrm{E}}$ is written as

$$
V_{\mathrm{E}}(\boldsymbol{u})=-\frac{1}{8 \pi} \varepsilon_{\mathrm{a}}(\boldsymbol{u} \cdot \boldsymbol{E})^{2}
$$

where $\boldsymbol{E}$ is the electric field and $\varepsilon_{\mathrm{a}}\left(=\varepsilon_{\|}-\varepsilon_{\perp}\right)$ is the difference of the static dielectric constants parallel and perpendicular to the nematic axis. The mean field potential $V_{\mathrm{MF}}$ for rigid rodlike polymers is written by the Onsager theory ${ }^{21}$;

$$
V_{\mathrm{MF}}=2 c d L^{2} k_{\mathrm{B}} T \int \sin \left(\boldsymbol{u}, \boldsymbol{u}^{\prime}\right) f(\boldsymbol{u} ; t) d^{2} \boldsymbol{u}^{\prime}
$$

where $c$ is the number of molecules in a unit volume. $L$ and $d$ are the length and diameter of polymer respectively and $k_{\mathrm{B}}$ and $T$ are the Boltzmann constant and the absolute tempera- 
ture.

The rotational diffusivity, $\bar{D}_{\mathrm{r}}$, in nematic phase is specified as follows;

$$
\begin{aligned}
\bar{D}_{\mathrm{r}} & =v_{1} D_{\mathrm{ro}}\left(c L^{3}\right)^{-2} \\
\times & \left\{\frac{4}{\pi} \int d^{2} \boldsymbol{u}_{1} d^{2} \boldsymbol{u}_{2} f\left(\boldsymbol{u}_{1} ; t\right) f\left(\boldsymbol{u}_{2} ; t\right) \sin \left(\boldsymbol{u}_{1}, \boldsymbol{u}_{2}\right)\right\}^{-2} \\
& =v_{1} D_{\mathrm{ro}}\left(c L^{3}\right)^{-2}\left(1-S^{2}\right)^{-2}
\end{aligned}
$$

where $v_{1}$ is the numerical constant of order unity and $D_{\text {ro }}$ is the rotational diffusivity of a rod-like polymer in a dilute solution of rods. The second term is the effect of the concentration and the final term is the effect of the orientation of rods. $\bar{D}_{\mathrm{r}}$ is the function of the order parameters, $S$, and the reference viscosity, $\eta^{*}$ :

$$
\eta^{*}=\frac{c^{*} k_{\mathrm{B}} T}{6 D_{\mathrm{r}}^{*}}
$$

Miesowicz viscosities are obtained by measuring the viscosity of the shear flow while keeping the director $\boldsymbol{n}$ in a certain direction by strong electric field. ${ }^{22}$ They depend on the relative orientations of the rods with respect to the velocity vector. The "a" orientation refers to rods oriented in the neutral direction of the shear flow. The " $b$ " orientation refers to the rod's orientation in the direction of the shear flow. The "c" orientation is oriented perpendicular to the shear flow. These viscosities are related to the Leslie coefficients, $\alpha_{i}$, and are predicted to be a function of the order parameter and dimensionless concentration as follows;

$$
\begin{aligned}
& \eta_{\mathrm{a}}=\frac{1}{2} \alpha_{4}=\eta^{*} C^{3}\left(1-S^{2}\right)^{2}(1-S) \\
& \eta_{\mathrm{b}}=\frac{1}{2}\left(\alpha_{3}+\alpha_{4}+\alpha_{6}\right)=\eta^{*} C^{3}\left(1-S^{2}\right)^{2} \frac{(1-S)^{2}}{(1+S / 2)}
\end{aligned}
$$

$$
\begin{aligned}
\eta_{\mathrm{c}} & =\frac{1}{2}\left(-\alpha_{2}+\alpha_{4}+\alpha_{5}\right) \\
& =\eta^{*} C^{3}\left(1-S^{2}\right)^{2} \frac{(2 S+1)^{2}}{(1+S / 2)}
\end{aligned}
$$

which give the correct ordering $\eta_{\mathrm{c}}>\eta_{\mathrm{a}}>\eta_{\mathrm{b}}$ for low molecular weight liquid crystals and $C$ is the dimensionless concentration $\left(=c / c^{*}\right)$. No measurement on the Miesowicz viscosities has been reported for polymeric liquid crystals.

The Doi theory can generally describe the non-linear viscoelastic behavior of both the isotropic and nematic phases. The molecular approach makes possible a description of macroscopic flow properties through molecular parameters.

\section{EXPERIMENTAL}

\section{(a) Materials and Solutions}

The polymer used in this study was poly( $p$-phenylene terephthalamide) (PPTA) ("Kevlar" pulp by du Pont, density $=1.43$ $\mathrm{g} \mathrm{cm}^{-3}$ ). PPTA can be dissolved in polar solvents such as $N, N$-dimethylacetamide, or strong acids such as concentrated sulfuric acid or chlorosulfonic acid. ${ }^{23}$ PPTA was dissolved in $100 \%$ sulfuric acid, obtained from a mixture of $96 \% \mathrm{H}_{2} \mathrm{SO}_{4}$ (by Mallinckrodt Inc.) and Oleum $\quad\left(65 \% \quad \mathrm{SO}_{3}+35 \% \quad \mathrm{H}_{2} \mathrm{SO}_{4}\right.$, by Merck). PPTA was well washed with pure acetone and then many times with a distilled water to remove oil and other impurities. It was dried in vacuum oven at $90^{\circ} \mathrm{C}$ for two days. The molecular weight of PPTA was measured indirectly from the inherent viscosity in $96 \%$ sulfuric acid at a concentration of $c=0.5 \mathrm{~g} \mathrm{dl}^{-1}$ by Cannon and Fenske viscometer at $30^{\circ} \mathrm{C}$. The value of the inherent viscosity was compared with the data of molecular weight reported by Arpin and Strazielle. ${ }^{24}$ The inherent viscosity of PPTA was about $5.12 \mathrm{~g} \mathrm{dl}^{-1}$, corresponding to a molecular weight $\bar{M}=35000$. Solutions of $1 \quad(=1.28$ vol $\%)-12 \mathrm{wt} \%$ (14.93 vol\%) PPTA in sulfuric acid were prepared in the dry nitrogen environment. In order to remove very small bubbles, the PPTA solutions were placed in a vacuum oven at $30-40^{\circ} \mathrm{C}$ for one or two days. 


\section{(b) Apparatus}

A capillary rheometer was used to determine the steady-state viscosity at a certain concentration. The schematic diagram of the experimental apparatus is shown in Figure 1. The equipment used here includes a nitrogen tank, a capillary tube, a mercury manometer and a oil bath for the temperature control at $50^{\circ} \mathrm{C}$. To keep the constant pressure difference between the exit and inlet of the capillary tube, two line regulators and a purged line regulator are used. The temperature controller in the oil bath is used to make the constant temperature with the error range of $0.3^{\circ} \mathrm{C}$. The Miesowicz viscosity, $\eta_{b}$, one of the three principal 'locked director viscosity' for LCPs, is measured with the director perpendicular to the velocity gradient in a flow apparatus. In order to measure $\eta_{b}$, the PPTA solution is driven by a constant pressure difference through a rectangular capillary with dimensions of $120 \times$ $25 \times 1 \mathrm{~mm}$. The ratio of length to hydraulic radius of capillary is enough to neglect the end effects, such as extension and contraction and other friction. The upper and lower copper plates were covered with Teflon tapes in order to supply the DC electric field. Since the viscosity measured with the rectangular capillary shows different value from that of the circular capillary, a correction factor is introduced to obtain the actual viscosity. This shape factor depends on the power law index and aspect ratio $W / H$ where $W$ and $H$ are the width and depth of the duct. ${ }^{25}$ If the LCPs are placed in an electric field, the directors will be induced to reorientate through the interaction between the anisotropic molecular dielectricity and the electric field. The reorientation will cause modifications to the electrical and optical properties of LCPs. ${ }^{26}$ With no application of an electric field, the directors will be locked perpendicular to the plates in case of negative dielectric anisotropy of LCP. ${ }^{22}$ When an electric field strength reaches a certain value, the directors start to move. This applied voltage is called a threshold voltage. It is very difficult to supply the electric field above $2200 \mathrm{~V} \mathrm{~cm}^{-1}$, because of electric instability such as a sudden

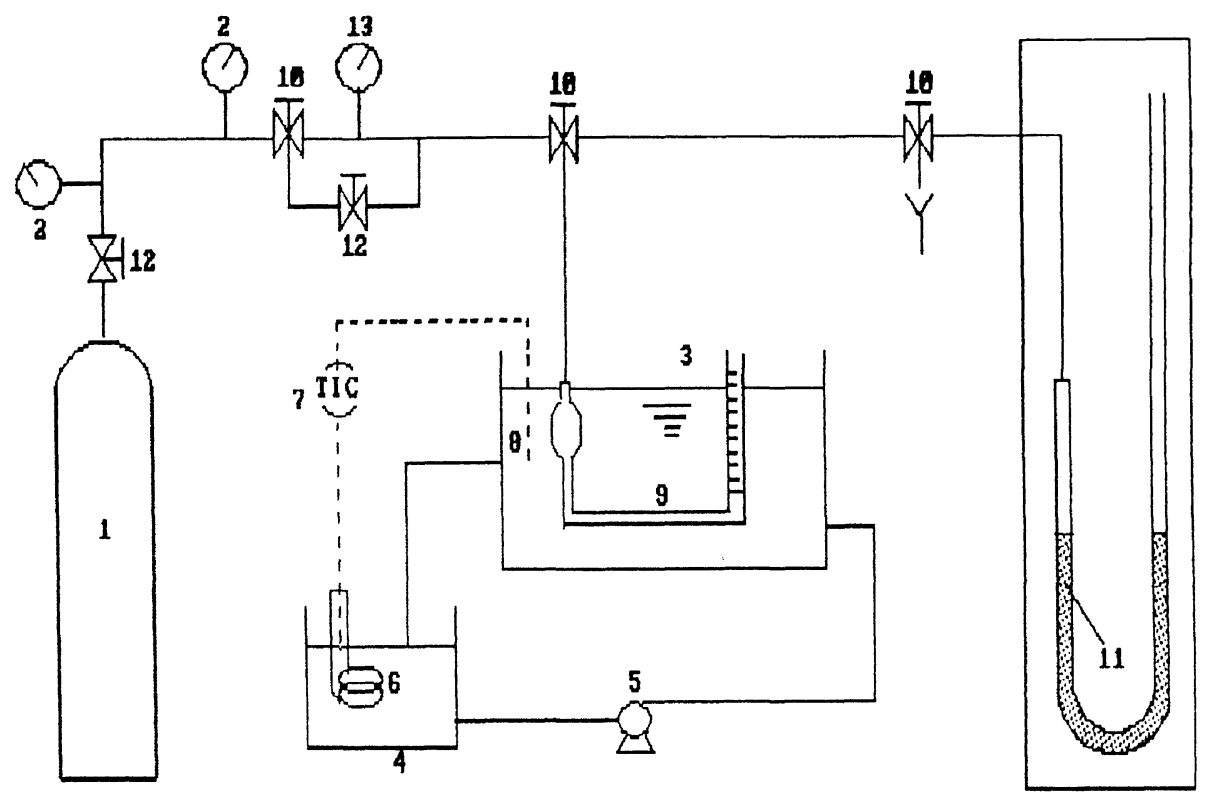

Figure 1. Schematic diagram of the experimental apparatus. 1) $\mathrm{N}_{2}$ bomb; 2) line regulator; 3) oil reservoir; 4) oil bath; 5) circulation pump; 6) heater; 7) temperature controller; 8) sensor; 9) capillary viscometer; 10) three way valve; 11) mercury manometer; 12) line valve; 13) purged line regulator. 
decrease in voltage and electric current generation.

\section{POLARIZED LIGHT MICROSCOPY}

Optical textures of PPTA solutions were observed with a polarized light microscope (CARL-ZEISS Co., Model No. D-7082, × 80) in the range from $30^{\circ} \mathrm{C}$ to $55^{\circ} \mathrm{C}$ at an increasing rate of $1^{\circ} \mathrm{C} / 5 \mathrm{~min}$. Polarized light microscopy was used to find the critical concentration at the fixed temperature of $50^{\circ} \mathrm{C}$. The critical concentration increased with temperature. ${ }^{27,28}$ For less than $6 \mathrm{wt} \%(=7.59 \mathrm{vol} \%)$ PPTA solution, the phase was isotropic but for the $7 \mathrm{wt} \%(=8.83 \mathrm{vol} \%)$ solution, the opalescent state was observed at room temperature, indicating the initiation of phase transition. This solution became isotropic when the

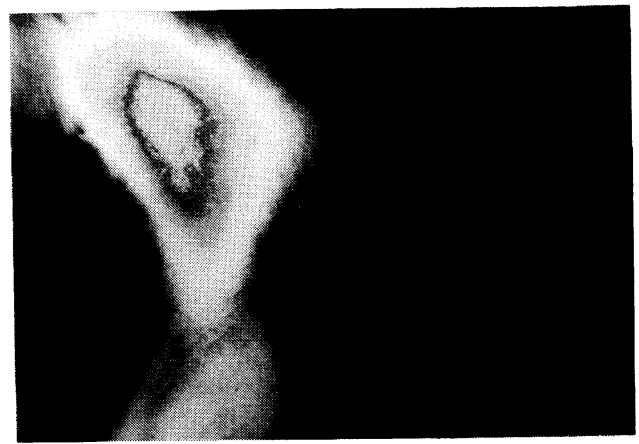

(a)

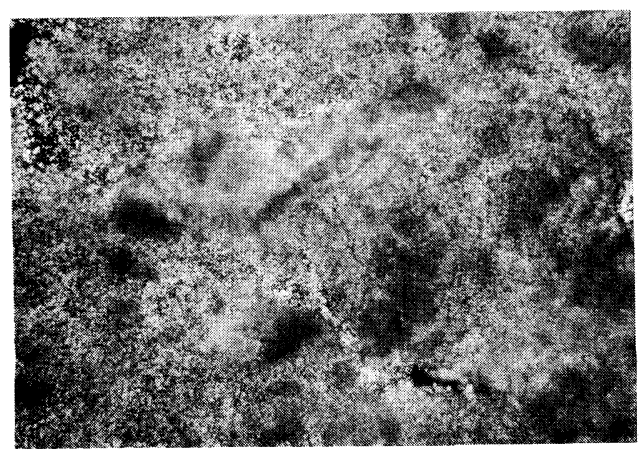

(b)

Figure 2. Polarized light microscopy for PPTA solutions. (a), onset of the anisotropy $\left(9 \mathrm{wt} \%\right.$ at $\left.50^{\circ} \mathrm{C}, \times 80\right)$; (b), anisotropy $\left(12 \mathrm{wt} \%\right.$ at $\left.50^{\circ} \mathrm{C}, \times 80\right)$. temperature was raised to $40^{\circ} \mathrm{C}$. The $8 \mathrm{wt} \%$ $(=10.06 \mathrm{vol} \%)$ solution at $42^{\circ} \mathrm{C}$ showed a mixed state of anisotropic and isotropic phases. As the temperature was increased, the opalescent state was observed at $46.5^{\circ} \mathrm{C}$ and isotropic phase at $47^{\circ} \mathrm{C}$. $9 \mathrm{wt} \%(=11.29 \mathrm{vol} \%)$ solution started to show the biphasic state (Figure 2(a)), and $12 \mathrm{wt} \% \quad(=14.93 \mathrm{vol} \%)$ solution was in the anisotropic phase (Figure 2(b)) at $50^{\circ} \mathrm{C}$. The photomicrograph of anisotropic PPTA solution clearly showed a nematic liquid crystalline texture. ${ }^{29}$ It was hard to measure the exact critical concentration, but it could be around $9 \mathrm{wt} \%(=11.29 \mathrm{vol} \%)$ at $50^{\circ} \mathrm{C}$. The data obtained from the capillary viscometer showed almost the same concentration.

\section{RESULTS AND DISCUSSION}

As a reference state, the exact critical concentration, $c^{*}$, should be known to compare the theoretical prediction and experimental data. According to Onsager, ${ }^{21}$ it can be calculated from $c^{*}=5.1 / x$ where $x(=L / d)$ is the axial ratio of a rodlike molecule. The value is reasonable within $2 \%$ error for $x>10$. According to Flory $^{30} c^{*}=8(1-2 / x) / x$ is given. Note that the critical concentration in the Onsager and Flory theories are independent of temperature, i.e., an athermal system. The molecular weight of PPTA is about 35000 and its contour length, $L$, is $1764 \AA$. According to Arpin and Strazielle ${ }^{24}$ the diameter, $d$, of PPTA is $12 \AA$ in dilute solution. Therefore the theoretical, $c^{*}$, is $3.5 \mathrm{vol} \%$ by the Onsaer theory and $5.4 \mathrm{vol} \%$ by the Flory. Of course, this concentration may change due to the axial ratio of the polymer. The measured value was found to be about $9 \mathrm{wt} \%(=11.29$ vol\%). The experimental value was larger than the theoretical value. The difference might be caused by chain rigidity, inter and intramolecular interactions and others.

Figure 3 is a plot of viscosity, $\eta$, versus shear rate, $\dot{\gamma}$, measured by the circular capillary 


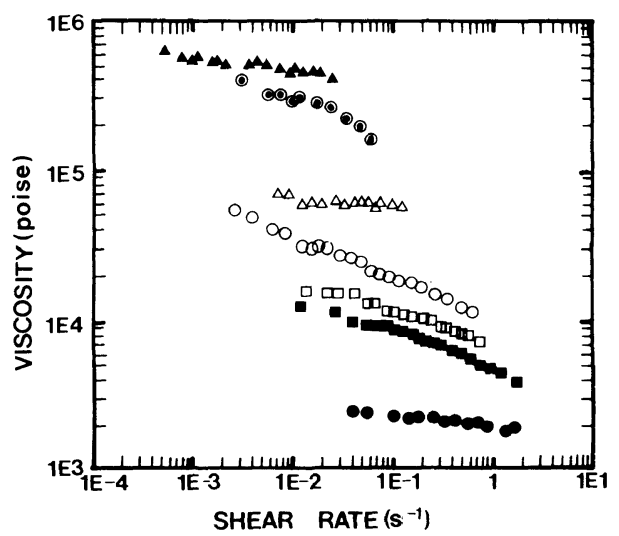

Figure 3. Variations of the shear viscosity with shear rate for anisotropic PPTA solutions at $50^{\circ} \mathrm{C}$., $3 \mathrm{wt} \% ; \triangle$, $6 \mathrm{wt} \% ; \boldsymbol{\Delta}, 9 \mathrm{wt} \% ; \odot, 9.5 \mathrm{wt} \% ; \bigcirc, 10 \mathrm{wt} \% ; \square, 11 \mathrm{wt} \%$; 口, $12 \mathrm{wt} \%$.

viscometer at $50^{\circ} \mathrm{C}$. It shows three regions discussed by Onogi and $\mathrm{Asada}^{31}$; the shear thinning region at low shear rate, the plateau like a Newtonian fluid and the shear thinning region at high shear rate. The solution with the isotropic phase did not exhibit these three regions. The flow of LCP solution through a rectangular slit under an electric field at low shear rate involved complicated hydrodynamics of nematics like low molecular weight liquid crystals. In order to make the effect of electric field more significant than that of shear flow, the LCP solution was subjected to a very low shear rate. The viscosity of LCP solution shows different values for different electric field potential. The Miesowicz viscosity, $\eta_{b}$, is obtained by taking the saturated viscosity beyond the threshold voltage. Figure 4 represents the change of viscosity according to the applied voltage above threshold voltage for the solution with anisotropic phase. The isotropic solutions have almost constant viscosities up to the high voltage. Even though the solution of $6 \mathrm{wt} \%(=7.59 \mathrm{vol} \%)$ exhibits some drop of viscosity in the vicinity of high electric field (about $2000 \mathrm{~V} \mathrm{~cm}^{-1}$ ), the solution of $3 \mathrm{wt} \%(=3.83 \mathrm{vol} \%)$ PPTA is not influenced by the applied voltage. This may indicate that the solution with the isotropic phase is not

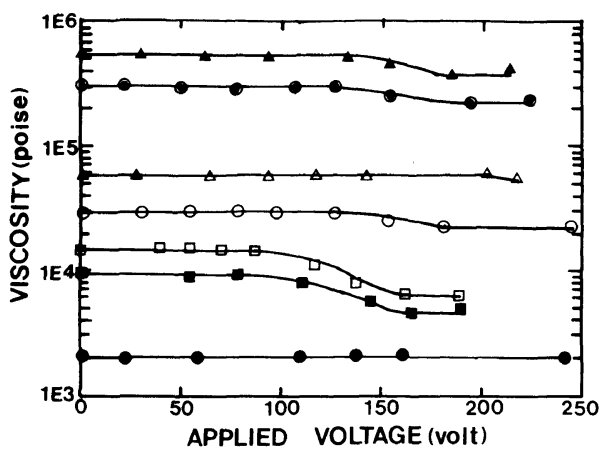

Figure 4. Plots of viscosity and applied voltage for PPTA isotropic and anisotropic solutions at $50^{\circ} \mathrm{C}$. The saturated viscosities denote the Miesowicz viscosity, $\eta_{\mathrm{b}}$. $-3 \mathrm{wt} \%$; $\triangle, 6 \mathrm{wt} \% ; \Delta, 9 \mathrm{wt} \%, \odot, 9.5 \mathrm{wt} \% ; \bigcirc, 10 \mathrm{wt} \%, \square, 11 \mathrm{wt} \%$; 口, $12 \mathrm{wt} \%$.

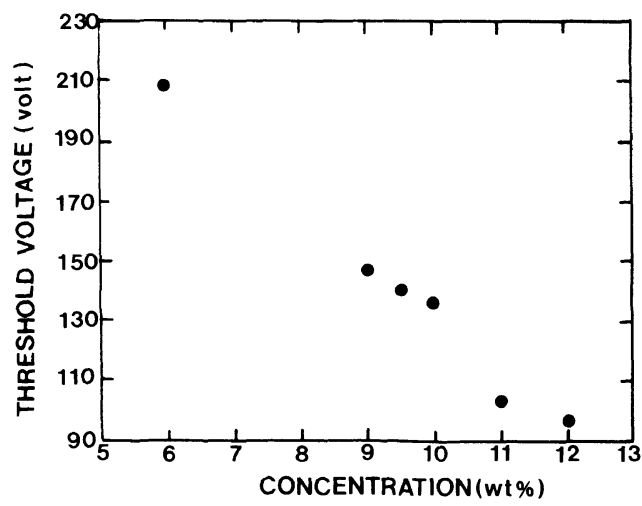

Figure 5. Variations of threshold voltage with concentration for PPTA solutions at $50^{\circ} \mathrm{C}$.

influenced by the electric field as much as that with the anisotropic phase. However the solution in anisotropic state has a lower viscosity with an applied voltage and reaches a saturated viscosity. This may be explained as follows; if rods have the orientation, they will be easily fixed by an electric field. If not, however, they will not be fixed by even high electric field. As indicated in Figure 5, the solution of $12 \mathrm{wt} \%$ PPTA showed the lowest threshold voltage. This indicates that it is easily influenced by an electric field when the orientation degree of the rod-like molecules is high. The parameters in the Doi theory such as the order parameter, $S$, and the rotation- 


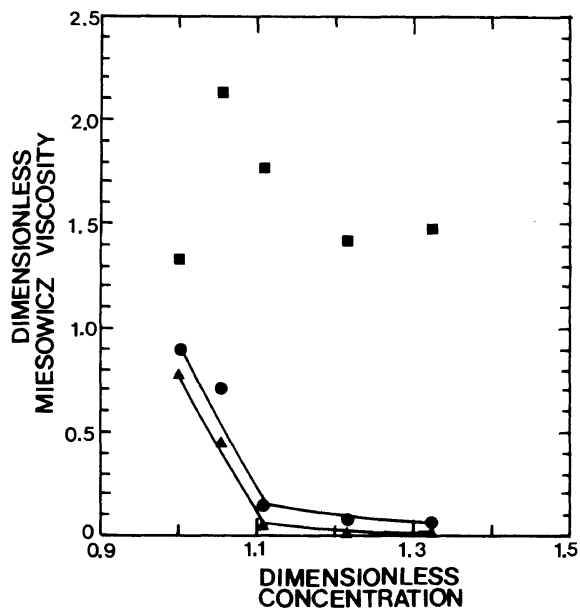

Figure 6. Dimensionless Miesowicz viscosity vs. dimensionless concentration for PPTA solutions at $50^{\circ} \mathrm{C}$. $\eta_{\mathrm{a}} / \eta^{*} ; \boldsymbol{\Delta}, \eta_{\mathrm{b}} / \eta^{*} ; \mathbf{\square}, \eta_{\mathrm{c}} / \eta^{*}$

al diffusivity, $\bar{D}_{\mathrm{r}}$, can be evaluated from the Miesowicz visocisty, $\eta_{\mathrm{b}}$, which is experimentally measured under the influence of an electric field. The other Miesowicz viscosities, $\eta_{\mathrm{a}}$ and $\eta_{\mathrm{c}}$, are also calculated using eq 8-10. As shown in Figure $6, \eta_{\mathrm{b}}$ and $\eta_{\mathrm{a}}$ decrease sharply with the concentration and level off to a constant value. The magnitudes of viscosities are in the order $\eta_{\mathrm{c}}>\eta_{\mathrm{a}}>\eta_{\mathrm{b}}$ for all concentrations in anisotropic state. The same order is also shown for low molecular weight liquid crystals. ${ }^{15}$ However, $\eta_{\mathrm{c}}$ exhibited a peculiar form different from the theory and that of low molecular weight liquid crystals. This difference between experimental and theoretical values of $\eta_{c}$ may be caused by biphasic structures. That is, the Doi and Marrucci theory may possibly apply separately to the homogeneous phase of isotropy or anisotropy, but not to the biphasic equilibrium mixture.

Figure 7 shows the variation of order parameter with dimensionless concentration of PPTA solutions. The order parameter increases with concentration and levels off. This indicates that the rod-like molecules do not perfectly orient perpendicular to the velocity gradient. The Doi and Edwards theory gives a lower

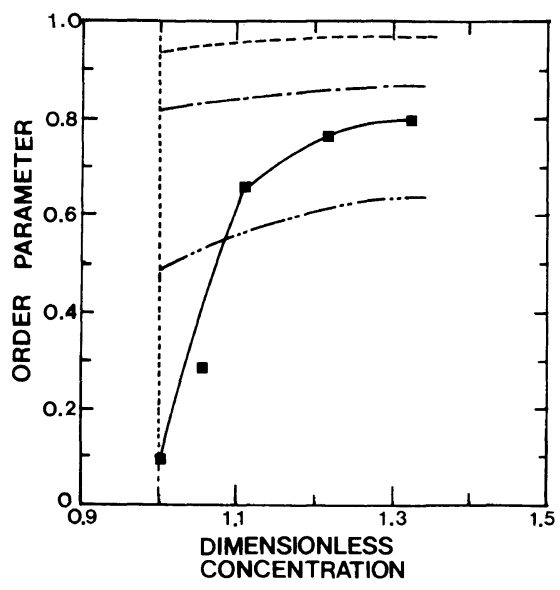

Figure 7. Variations of the order parameter with the dimensionless concentration for PPTA solutions at $50^{\circ} \mathrm{C}$. $\square$, experimental values; - - - - , from Doi theory; - - - , from Flory theory; ------, from Onsager theory.

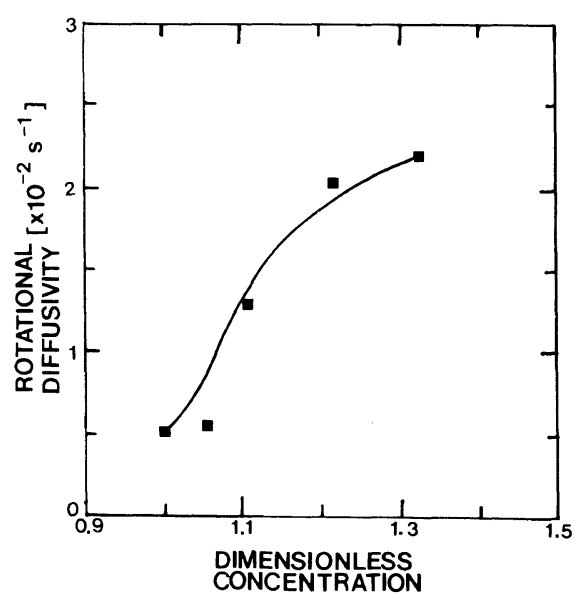

Figure 8. Rotational diffusivity $v s$. dimentionless concentration for PPTA solutions at $50^{\circ} \mathrm{C}$. $\square$, experimental values.

value of the order parameter at the critical concentration than the Onsager theory, ${ }^{21}$ and the Flory and Ronca theory ${ }^{32}$ gives the highest value. At a higher concentration, the experimental value corresponds nearly to that of the Onsager theory.

Figure 8 shows that the rotational diffusivity, $\bar{D}_{\mathrm{r}}$, increases with the dimensionless concentration and levels off. Generally, the rotational diffusivity decreases with concentration for 
semidilute solutions in which only concentrations are taken into consideration. When the orientations of molecules become important above a certain concentration, a rod-like molecule will have a larger diameter of the tube which gives a free space for the movement of one molecule. This effect is called tube dilation. ${ }^{33}$ Therefore, it can be said that rotational diffusivity increases with concentration because of the orientation of molecules above a certain critical concentration.

\section{CONCLUSIONS}

The critical concentration for the onset of liquid crystalline behavior was determined by using a polarized light microscopy. The concentrations in this study to evaluate $S$ and $\bar{D}_{\mathrm{r}}$ are in the anisotropic range above the critical concentration. For a solution in the anisotropic state, the Doi and Edwards theory fits very well the experimental data for the steady shear flow with or without an electric field. As the electric field strength became higher, the viscosity decreased above a threshold voltage at which the directors just began to change. Threshold voltage decreased with concentration in anisotropic state but did not change for the isotropic state. The experimental values of $S$ increased with concentration and were smaller than the values given by the Onsager theory and by the Flory and Ronca theory. The discrepancy between theory and experiment may be due to the factors such as flow and electric instability, molecular rigidity, polydomain structure (the Doi theory assumes monodomain), wall effects, etc. The increase of $\bar{D}_{\mathrm{r}}$ with concentrations can be explained by the 'tube dilation' which indicates the easy rotation of a rod-like molecule when the molecules are aligned in a direction above a certain critical concentration.

\section{REFERENCES}

1. S. L. Kwolek, U.S. Patent, 3671542 (1972).
2. H. Biades, U.S. Patent, 3767756 (1973).

3. D. G. Baird, J. Rheol., 24, 465 (1980).

4. R. E. Jerman and D. G. Baird, J. Rheol., 25275 (1981).

5. M. Doi, J. Polym. Sci., Polym. Phys. Ed., 19, 229 (1981).

6. M. Doi and S. F. Edwards, J. Chem. Soc., Faraday Trans. 2, 74, 560 (1978).

7. M. Doi and S. F. Edwards, J. Chem. Soc., Faraday Trans. 2, 74, 918 (1978).

8. G. Marrucci, Mol. Crystal. Liq. Cryst., 72, 153 (1982).

9. Y. Toyoshima, N. Minami, and M. Sukigara, Mol. Cryst. Liq. Cryst., 35, 325 (1976).

10. F. Ozaki, T. Ogita, and M. Matsuo, Macromolecules, 14, 299 (1981).

11. N. S. Murthy, J. R. Knox, and E. T. Samulski, J. Chem. Phys., 64, 4835 (1976).

12. A. Abe and T. Yamazaki, Macromolecules, 22, 2145 (1989).

13. M. L. Sartirana, E. Marsano, E. Bianchi, and A. Cifferi, Macromolecules, 19, 1176 (1986).

14. A. B. Metzner and G. M. Prilutski, J. Rheol., 30, 661 (1986).

15. M. Miesowicz, Mol. Cryst. Liq. Cryst., 97, 1 (1983).

16. A. G. Chmielewski, Mol. Cryst. Liq. Cryst., 132, 339 (1986).

17. K. Skarp, S. T. Lagerwall, and B. Stebler, Mol. Cryst . Liq. Cryst., 60, 215 (1980).

18. S. Holmstrom and S. T. Lagerwall, Mol. Cryst. Liq. Cryst., 38, 141 (1977).

19. N. Kuzuu, M. Doi, J. Phys. Soc. Jpn., 52, 3486 (1983).

20. N. Kuzuu, M. Doi, J. Phys. Soc. Jpn., 53, 1031 (1984).

21. L. Onsager, Ann. N.Y. Acad. Sci., 51, 627 (1949).

22. P. G. de Gennes, "The Physics of Liquid Crystals," Clarendon Press, Oxford, 1974.

23. J. R. Schaefgen, T. I. Bair, J. W. Ballou, S. L. Kwolek, P. W. Morgan, M. Panar and J. Zimmerman, "Ultra-High Modulus Polymers," A. Ciferri and I. M. Ward, Eds., Applied Sci. Publishers, London, 1978, p 173.

24. M. Arpin and C. Strazielle, Polymer, 18, 591 (1977).

25. S. Middleman, "Fundamental of Polymer Processing," McGraw-Hill, New York, 1977.

26. K. R. Welford and J. R. Sambles, Mol. Cryst. Liq. Cryst., 147, 25 (1987).

27. Y. C. Lee, M.Ch.E. Thesis, KAIST (1989).

28. B. C. Kim, S. S. Hwang, and K. U. Kim, Intern. Polym. Proc., 2, 28 (1987).

29. D. Demus and L. Richter, "Textures of Liquid Crystals," Verlag Chemie, New York, 1978.

30. P. J. Flory, Proc. R. Soc. London, Ser., A, 234, 73 (1956).

31. Y. Onogi and T. Asada, 8th Int. Cong. Rheol., 
Liquid Crystalline Polymer in an Electric Field

Naples, 1980, Rheology, Vol. 1, G. Astarita, G. Marrucci, and L. Nicolais, Eds., Plenum Press, New York, 1980, p. 127.

32. P. J. Flory, and G. Ronca, Mol. Cryst. Liq. Cryst.,
54, 289 (1979).

33. M. Doi and S. F. Edwards, "The Theory of Polymer Dynamics," Clarendon Press, Oxford, 1986. 